Before any major dietary changes can be recommended it remains to be clarified which component(s) of milk are responsible. None the less, it seems advisable for adults to drink milk only in moderate quantities.

We thank Professor K Villako for the idea of the study and associate professors $M$ Uusküla for his help in collecting the material, T Sahi for advice and reading the manuscript, and L-M Tooding for statistical analysis.

1 Segall JJ. Hypothesis: is lactose a dietary risk factor for ischaemic heart disease? Int $\mathcal{f}$ Epidemio 1980;9:271-6.

2 Isokoski M, Sahi T, Villako K, Tamm A. Epidemiology and genetics of lactose malabsorption. Ann Clin Res 1981;13:164-8.

3 Schlesselmann JJ. Case-control studies. Design, conduct, analysis. Oxford: Oxford University Press, 1982:354.

4 Engelman L. Stepwise logistic regression. In: Dixon WJ, et al, eds. BMDP statistical software Berkeley: University of California Press, 1981:330-41

(Accepted 3 September 1987)

Laboratory of Enterology, Institute of General and Molecular Pathology, Tartu State University, 202400 Tartu, Estonia, USSR

$M$ LEMBER, MD, research fellow

A TAMM, MD, head of laboratory

Correspondence to: Dr Tamm.

\section{Implications of two newly opened ice rinks on an accident and emergency department}

Previous studies have reported many injuries sustained at ice rinks. ${ }^{12} \mathrm{I}$ report a study prompted by the almost simultaneous opening of a $60 \times 30 \mathrm{~m}$ Olympic rink, currently the largest in the United Kingdom, and a $38 \times 22 \mathrm{~m}$ "family fun rink" in the catchment area of this hospital.

\section{Methods and results}

Injuries treated at this department during the six months after the rinks were opened were monitored to assess the number and nature of injuries resulting from skating, the cost of treating them, and the measures that might be taken to make skating safer.

A total of 636 patients ( 268 male and 368 female) presented to the department. Their mean age was 20 (range 5-81), and $429(68 \%$ ) were aged $11-20$. Seventy one patients were brought to the hospital by ambulance. Most patients (501) were injured as a result of direct contact with the ice or barrier; 75 were injured by twisting or stretching while falling and 49 by direct contact with the blade of a skate; nine presented with blisters caused by ill fitting skates; and one had an acute attack of asthma and one was winded. The table shows the nature of the injuries. The commonest injuries were bruises to the knee (12\%) and head (12\%) and fractures of the wrist $(8 \%)$.

Altogether 447 patients had a radiographic examination. Most patients (410) were discharged, 190 were reviewed, and 36 were admitted as inpatients

The mean weekly attendance at the ice rinks was 14204 at the larger rink and 2103 at the smaller. The mean proportion of skaters who were treated was $0 \cdot 16 \%$ a week. The correlation coefficient of the percentage of skaters injured against the weekly attendance figures for the rinks was $-0 \cdot 36$.

On the assumption that it costs $£ 3.25$ per mile for ambulance journeys, $£ 12.60$ per patient for basic accident and emergency care, $£ 25.40$ per unit for radiology, and $£ 75$ per patient day for those admitted to hospital, the estimated total cost to the area health board of treating these patients was $£ 43276$, or $£ 68$ per patient.

\section{Comment}

During the six months of the study 20317 new patients were treated in the accident and emergency department. The 636 patients from the ice rinks therefore constituted $3 \%$ of the total, compared with $757(4 \%)$ patients who were injured in road accidents in the same period. Only $0.16 \%$ of the people attending the ice rinks needed hospital treatment, but this represented many injuries because of the large number of people who go skating. The proportion of skaters injured did not correlate with the number attending the rinks. Thus it is uncertain whether limiting the number of skaters at a rink at any one time would reduce their chance of being injured.

The severity of injuries might be reduced if skaters wore protective clothing. Knee and head injuries, the most common injuries identified in the study, could be lessened by the use of knee pads and helmets; many ice rinks in Canada insist that all skaters under the age of 16 wear head protection.

This study showed that a newly opened ice rink will impose appreciable extra work on the nearest accident and emergency department. The cost of treating these patients is considerable and should be taken into account when new ice rinks are planned.

I thank Mr J Shaw; the clerical, nursing, and medical staff of this department; the management of Dundonald Ice Bowl and Crystals Arena, Bangor; and Mrs V Hastings and Mrs M Onesti for their typing.

1 Horner C, McCabe MJ. Ice skating and roller disco injuries in Dublin. B J Sports Med 1984;18 207-11

2 Prescott MV. The effect of opening an ice rink on the accident and emergency department of a district general hospital. Arch Emerg Med 1986;3:107-10

(Accepted 23 September 1987)

Accident and Emergency Department, Ulster Hospital, Dundonald, Northern Ireland

$P$ FREELAND, MRCP, FRCS, senior registrar in accident and emergency medicine

Injuries received at ice rinks

\begin{tabular}{|c|c|c|c|c|c|c|}
\hline \multirow[b]{2}{*}{ Site } & \multirow[b]{2}{*}{ Total No } & \multicolumn{5}{|c|}{ Nature of injury } \\
\hline & & Fracture & Dislocation & Laceration & Bruise & Strain \\
\hline Knee & 131 & 4 & 2 (Patella) & 4 & 79 & 42 \\
\hline Wrist & 96 & 51 & & 2 & 4 & 39 \\
\hline Head & 86 & 2 & & 10 & 74 & \\
\hline Hand and fingers & 64 & 12 & 1 & 37 & 2 & 12 \\
\hline Face & 49 & 2 (Nose) & & 38 & 9 & \\
\hline Ankle & 41 & 12 & & & 2 & 27 \\
\hline Elbow & 32 & 11 & 1 & & 20 & \\
\hline Shoulder & 26 & 7 & 7 & & 12 & \\
\hline Scaphoid & 23 & 1 & & & 22 & \\
\hline Pelvis & 19 & 7 (Coccyx) & & 2 & 10 & \\
\hline Lumbar spine & 11 & & & 2 & 6 & 3 \\
\hline Foot & 11 & & & 6 & 5 & \\
\hline Tibia or fibula & 11 & 9 & & & & 2 \\
\hline Chest & 9 & & & 1 & 8 & \\
\hline Fibula & 7 & 7 & & & & \\
\hline Neck & 4 & & & & & 4 \\
\hline Miscellaneous & 16 & & & & & \\
\hline Total (\%) & 636 & $125(20)$ & $11(2)$ & $102(16)$ & $253(40)$ & $129(20)$ \\
\hline
\end{tabular}

